Cambridge Examinations leads me erroneously to think that the proofs are expected to be given in the same order. In drawing this personal statement to a close, I may say that I am not singular in the view I took, as I learn from several gentlemen who have spoken to me ou the point, and indeed, had it not been that the authorities* of University College School thought I had some ground for my views, I should have kept silence altogether. I believe the matter will come under the consideration of the proper authorities, and in their hands I am perfectly willing to leave the settlement of the question, if there be any need for a change.

University College School

R. TUCKER

\section{Science and the University of Cambridge}

ONE of the last sentences in your paragraph concerning the report of the Syndicate for providing better opportunities for the study of physical science in the University of Cambridge, though founded upon a partial misconception of the state of affairs, suggests what is probably the best solution of the difficulty. The colleges, if polled upon the simple question, "Shall we aid in promoting the study of physical science?" would, I believe, reply by a considerahle majority in the affirmative. It is upon the best mode of contributing that there is so much division of opinion; and this has caused the apparently "lame and impotent conclusion."

The question of taxing the college revenues is one of considerable difficulty; some colleges already support out of their corporate funds teachers of natural science, some have recently taxed themselves heavily to improve their buildings.

Most would think that non-resident fellows who do little for the college should be taxed more heavily than those who reside to do much work for no great amount of pay ; but to bring about this would require much alteration of statutes. The question, therefore, being so complicated, and there being, as I believe, a general willingness to contribute, if only a just and equitable mode of raising the funds can be devised, and proper control retained over them (for the University is not generallys considered to manage its property so well as the colleges), I believe that the difficulties would be most simply solved by the appointment of a commission composed of a few well-qualified persons, thoroughly acquainted with the University, to devise a scheme and to draw up an act for carrying it into effect.

St. John's College, Cambridge

\section{EXPLORATION OF CAVES AT SETTLE, YORKSHIRE}

$\mathrm{N}$ the mountain limestone of the West Riding are 1 many caves, some of which are empty, some traversed by water, which is silting up their lower chambers, while others are full up to the very roof with debris of various kinds. All have been, at some time or other, subterranean watercourses, and have been formed, partly by the friction of the substances set in motion by the current, but principally by the chemical action of the carbonic acid of the rain-water by which the insoluble carbonate of lime in the rock is converted into the soluble bicarbonate. Some have been inhabited, at various times, by man, and by wild beasts, and therefore may be expected to furnish valuable evidence of a condition of things that has now passed away. The last recorded case of their being used by man as a place of refuge was during the rebellion of 1745 , when the eldest son of one of the gentlemen in the neighbourhood was hidden in a large cave, in the fear that the Scotch would pass southwards in that direction instead of by the Preston route.

The gentlemen of the West Riding have formed a com. mittee for the systematic exploration of these caves, and will doubtless obtain from them evidence of the very highest archæological value, relating to a time of which we know next to nothing,-that begins with the disappearance of the mammoth, hyæna, and lion from Northern Europe,

* What strong views in favour of the modern methods are held by Prof. Key, may be seen from Prof. Hirst's preface to our Geometry. and extends as far down as the dawn of history in Britain, during which the neolithic and bronze-using races spread over Europe from the south-east. The older caves have been explored in many parts of Britain, while the pre-historic of the later have only been systematically examined in Somersetshire and Denbighshire by myself and Mr. Sanford. That the work in Yorkshire is planned well is clear from the following extracts from the Resolutions :-

That the following scheme, proposed by Sir James KayShuttleworth (chairman), be adopted, viz. :-

I. To examine the ground around the mouth of the caves for sigus of fire, implements, utensils, remnants of food, or traces of sepulture.

2. To make a survey of the caves in order to provide a plan of the interior drawn to scale, and of a sufficient size to enable a record to be made on it of the situation in which each thing is found.

3. To ascertain by one or more vertical excavations of limited extent what are the deposits chronologically arranged.

4. Then to proceed to examine these strata from the mouth of the cave inwards, so as to secure the discovery of all remains throwing any light on the history of each stratum.

5. To keep a record of the things discovered.

The first cave chosen by the committee is that found by Mr. Jackson, high up in a limestone cliff near Settle, on the coronation-day of our Queen, and which is therefore known as "the Victoria cave." It consists of a series of large chambers and passages, which are nearly filled to the roof with a reddish grey clay and stones. It must at one time have been of wonderful beauty, for there are the remains of massive stalactites, and of thick stalagmitic pavements; but now these are so decomposed by the carbonic acid that they are reduced to the condition of very soft mortar. Curiosity-hunters have also been doing their usual ruthless mischief. When it was first opened, Mr. Jackson obtained from a chamber at the original entrance a large series of ornaments and implements of bronze, iron, and bone, along with pottery and remains of animals. 'There are in his collection bronze fibulæ, iron spear-heads, iron nails, bone spoons, spindle whorls of stone and pottery, fragments of Samian ware, and other pottery turned in a lathe, cockle-shells, flint flakes, whetstones and stone balls. The remains found with these belong to the red deer, roebuck, pig, horse, and Celtic short-horn (Bos longifrons), sheep or goat, badger, fox, otter, and dog. There are also Roman coins of bronze and silver. All these were derived from a superficial deposit, and could not be assigned to an earlier date than that of the Roman occupation. The pottery was of the same kind as that so commonly found in the refuse heaps near Roman villas. It is worthy of note that the two domestic animals, the Celtic short-horn and the sheep or goat, were those that had been most abundantly used for food. The exploration committee resolved to follow up this discovery by a thorough examination of the cave, which they are able to undertake by the courteous permission of the owner, Mr. Stackhouse.

Outside the entrance of the cave, and at a lower level, is a small plateau composed of débris, which occupies the exact point where daylight could be seen through chinks, from the inside of one of the large chambers. As both the plateau and the chamber were undisturbed, the committee determined to begin work by removing the débris and making a new entrance into the cave. While this was being done, the following section was exposed. On the surface there was a layer of fragments of limestone that had fallen from the cliff above, two feet in thickness. Underneath was a layer of dark earth with stones about eighteen inches in thickness. It furnished large quantities of bones, nearly all of which had been used for food, and several articles of bronze, iron, or bone of the same kind and age as those I have already mentioned. The pottery is also of the same Roman character. Fragments of charcoal were also abundant, and stones bearing the 
marks of fire. There can be no doubt that this stratum marks the place where the dwellers in the cave, during Roman or immediately post-Roman times in Britain, kindled their fires and cooked their food. Underneath is a talus of limestone fragments detached from the cliff by atmospheric action, like the superficial accumulation. It is from six to seven feet in thickness. In some places the fragments were cemented together with a soft decomposing stalagmite. It rested on a layer of grey clay, of a thickness which at present has not been ascertained. At the bottom of the talus, and close to the entrance that is now being made into the chamber, there were found two rude flint flakes, a remarkably large lower jaw of bear, the broken bones of the Celtic shorthorn (Bos longifrons), and of the red-deer. On the 4 th April a most remarkable bone harpoon was dug out from the same horizon. It is between four and five inches in length, and is furnished with two barbs on each side, arranged opposite each other, composing the head of the implement. The base presents a form of attachment to the handle which, so far as my knowedge extends, is new to Britain. Instead of having a mere projection to catch the ligatures, there is a well-cut barb on either side that points in a contrary direction to those on the head. Were the bases of a barbed arrowhead and of a harpoon joined together, the resultant form would be analogous to the one in question. Therecan be no doubt from the position of these remains, that man occupied the spot before the accumulation of the overlying débris. Ample use for his harpoon he would find in the mere, now drained and turned into green fields, which are almost overlooked by the cave. So far as the work has proceeded there is no trace of metal at this horizon in the section.

The value of the evidence hitherto obtained lies in the fact that the Roman stratum is separated from the lower level, in which the flints, harpoon, and bear were found by the talus of angular stones. And this in a rough way enables a computation to be made of the date of the lapse of time between them, if we allow that for a considerable time past, immediately outside the historical epoch the disintegration of the cliff has been equal, in equal times. For since, in twelve hundred years, to put it at the lowest, only a thickness of twenty-four inches has been accumulated above the Roman remains, it would take three thousand six hundred years for a deposit of six feet to be formed, and thus the harpoon and flint stratum would be about four thousand years old. The accuracy of this calculation is indeed injured by the possibility that the winter cold was more intense, and the splitting action of the frost greater in Pre-, than in Post-Roman times. Nevertheless, the change from the Arctic severity of the post-glacial winter, to the climate which we now enjoy in Britain, has been so gradual, and has been spread over so long a period, that it may be assumed to have been very smali in so short a time as four or five thousand years.

This account is merely an outline of the results obtained up to April the $4^{\text {th }}$. The cave promises to be a rich one, and will probably add very much to our knowledge of the Pre-historic dwellers in Yorkshire.

\section{W. BOYD DAWKINS}

\section{THE ABRADING AND TRANSPORTING POWER OF WATER}

\section{I. - MECHANICAL PROPERTIES OF WATER}

$\mathrm{T} T$ is not my intention to lay down definite rules or formula regarding the flow of water, but rather, by drawing attention to generally-acknowledged facts, to throw out suggestions which may serve to lead to the discovery of some general laws of practical use to the hydraulic engineer.

In 1857 a paper was read by me before the Royal Society of Edinburgh, "On the Delta of the Irrawaddy," in which I expressed an opinion that depth somehow affected the abrading and transporting power of water.

livy experience of Indian rivers and canals during the succeeding ten years went to confirm this opinion, and before the Institution of Civil Engineers, as well as on two occasions before the British Association in 1868 and I 869 , I ventured to give expression to my views of this law, as affecting artificial rivers for irrigation, and the bridging of rivers which flow through the alluvial plains of Northern India.

In the Artizan there have appeared during the last six months several short articles bearing on the same subject, showing how all questions relating to flowing water are affected by this supposed law, which may be stated as follows: "the abrading and transporting power of water increases in some proportion as the velocity increases, but decreases as the depth increases."

The first question that arises in this inquiry is-What is water in a mechanical point of view?

This may be briefly answered by saying that it is a fluid, the particles of which, though easily separated, do again unite, and exert a certain affinity towards each other, and also to other bodies, so that a certain amount of power is necessary to effect a separation. The attraction of the particles of water to other bodies varies with different substances; for instance, in all bodies of a fatty nature the facility for wetting is very slight ; and different temperatures. also affect this property of water. This attraction or force is technically known as "skin friction," and deserves the most careful investigation; for it is owing chiefly, if not altogether, to the fact that water has the power of abrasion, and it is this property which introduces the most difficult problems that a naval architect has to solve.

The affinity of one set of particles of water to another set, may possibly be measured by noting the size of a drop of water which falls from a wetted surface of a given area. By thus determining accurately the weight of water a given area can support, some approximate results of an instructive character may be arrived at; but what adds to the complication of the question is, that the cohesion of the particles probably differs according to the temperature and the purity of the water experimented on. Thus, when water reaches the boiling point the affinity, it is believed, becomes very much lessened; and, again, it is thought that with pure or distilled water the particles probably have less affinity to each other than with water less pure. This impurity may arise from various causes; sewage, for example, would probably give much heavier drops from the same wetted area than rain water, in the same manner that drops of treacle are much larger than those of water; that is to say, the affinity, attraction, or cohesion of the particles is as a general rule increased by the introduction of foreign matter held in solution. With solid matter held in suspension a similar result is obtained, not by increasing the cohesion of the particles of water, but by increasing the surface area wetted; for each grain of foreign matter, be its shape what it may, must have all its surface in contact with the water. This probably explains how a drop of mud should be so much larger than one of water, and, at the same time, it may possibly explain why thick muddy water, or more properly speaking, liquid mud, with the same section and slope, cannot travel so fast as water.

From this it may reasonably be supposed, that when muddy water runs down an inclined plane, the solid particles cannot by their own gravity sink so rapidly towards the bottom as io overcome the power dragging them in a different direction. As a consequence, the flow of water is retarded by having solid matter held in suspension in some proportion according to the load. On large rivers where this proportion may be only ion or $\frac{1}{200}$. part of the weight of water in motion, the retarding force may not be appreciable by the most careful experiments; so when calculating, the discharge may be left out 